Mass spect romet $r$ i c st udy on i nact i vat i on mechani sm of spor e- for ming bacteria by l ow pressure surface-wave exci ted oxygen pl asma

\begin{tabular}{|l|l|}
\hline 著者 & Zhao Yi ng, Ogi no Aki hi sa, Nagat su Nasaaki \\
\hline $\begin{array}{l}\text { j ournal or } \\
\text { publ i cat i on ti t l e }\end{array}$ & Appl i ed Physi cs Let ter s \\
\hline vol une & 98 \\
\hline nunber & 19 \\
\hline page r ange & 191501 \\
\hline year & $2011-05-09$ \\
\hline 出版者 & Aner i can I nst i t ut e of Physi cs \\
\hline 権利 & ( C) 2011 Aner i can I nst i t ut e of Physi cs \\
\hline URL & ht t p: //hdl . handl e. net /10297/5652 \\
\hline
\end{tabular}




\title{
Mass spectrometric study on inactivation mechanism of spore-forming bacteria by low-pressure surface-wave excited oxygen plasma
}

\author{
Ying Zhao, Akihisa Ogino, and Masaaki Nagatsu ${ }^{\text {a) }}$ \\ Graduate School of Science and Technology, Shizuoka University, 3-5-1, Johoku, Naka-ku, \\ Hamamatsu 432-8561, Japan
}

(Received 29 December 2010; accepted 7 April 2011; published online 9 May 2011)

\begin{abstract}
In this letter, the etching phenomena of the spore-forming bacteria by oxygen plasma were investigated by using quadrupole mass spectrometry. The etching by-products of $\mathrm{H}_{2} \mathrm{O}$ and $\mathrm{CO}_{2}$ were obviously detected during the oxygen plasma irradiation by the multiple ion detection measurement. Inactivation of roughly $10^{6}$ spores population was achieved under almost the same reduced spore shapes for three different incident microwave powers. It is considered from the present results that the oxygen radical etching could cause damage to the germinant receptors located in the inner membrane inevitable for germination of spores, without any damage of the DNA in the cores. (C) 2011 American Institute of Physics. [doi:10.1063/1.3588036]
\end{abstract}

Inactivation mechanisms of spore-forming bacteria have been extensively studied to establish the plasma technique as a more effective sterilization tool. As for the low-pressure plasma sterilization, Boucher, et al. ${ }^{1}$ suggested the UV photons in plasma played an essential role on sterilization, and Bol'shakov, et al. ${ }^{2}$ reported that high densities of excited oxygen radicals induced chemical degradation of the biological materials followed by volatilization of the decomposition products. Moisan et al. ${ }^{3}$ insisted that chemical reactions, UVinduced damage or photodesorption and ion sputtering act synergistically, the inactivation by these processes were significantly faster than that by either process alone.

For the atmospheric pressure plasma sterilization, Park et $a l .^{4}$ concluded that the strong etching process observed is actually responsible for sterilization. Perni et al. ${ }^{5}$ claimed that oxygen atoms are identified as a major contributor in plasma inactivation with minor contributions from UV photons, $\mathrm{OH}$ radicals, singlet oxygen metastables, and nitric oxide. Kong et al. ${ }^{6}$ reviewed the recent experimental results on sterilization or biological effects of atmospheric plasmas and they also stated that the plasma-generated UV radiation and reactive species including free radicals and some ground state molecules such as peroxides and ozone play the important role on the inactivation of viruses and bacteria. At the present time, although there have been a lot of investigation on sterilization mechanisms of low temperature plasma, there are no fully understandable explanations as to the respective contributions of the various agents emanating from plasma to the bacterial killing process and this method is still under investigation.

In our previous works, we reported that a six-log reduction in spore population could be achieved only several minutes' irradiation with low-pressure oxygen surface-wave plasma. ${ }^{7}$ It was clearly seen from the scanning electron microscope (SEM) analysis that the sizes of spores were significantly reduced with increasing plasma irradiation time due to etching effect. ${ }^{8}$ But until now, the measurements were not sufficient to confirm that the irreversible damage of samples was resulted from the erosion because the observa-

\footnotetext{
a) Author to whom correspondence should be addressed. Tel.: 81-53-4781081. FAX: 81-53-478-1081. Electronic mail: tmnagat@ipc.shizuoka.ac.jp.
}

tion of the samples was performed by using the SEM after plasma treatment.

In this work, therefore, we carried out the mass spectrometric studies using quadrupole mass spectrometry (QMS) (Ref. 9) to confirm the etching event directly by measuring the etching by-products of micro-organisms during oxygen plasma irradiation and discussed the relation between the spore etching and sterilization characteristics, focusing upon the etching effect by oxygen radicals on the inactivation of microorganisms.

The experimental setup consists of a stainless steel cylindrical vacuum chamber of $300 \mathrm{~mm}$ in diameter and 300 $\mathrm{mm}$ in height with a microwave launcher and $2.45 \mathrm{GHz}$ microwave generator, as shown in Fig. 1. The output power of the microwave oscillator was varied from 0 to $1.5 \mathrm{~kW}$. The plasma discharges sustained in $\mathrm{O}_{2}$ at a gas flow rate of 100 SCCM (SCCM denotes cubic centimeter per minute at STP) and a pressure of $13.3 \mathrm{~Pa}$. The sterilization experiments were performed using nonpathogenic spore-forming bacteria, Geobacillus stearothermophilus (ATCC \#12980, Raven Biological Laboratories), as the biological indicator (B.I.). The population of spores pasted on an oblong polished stainless steel disk was $1.7 \times 10^{6}$. These samples were placed in a glass Petri dish on the stage about $10 \mathrm{~cm}$ below the quartz window. The top of the glass Petri dish was covered with a stainless steel shutter having $100 \mathrm{~mm}$ in diameter and $5 \mathrm{~mm}$ in thickness to block the plasma particles and plasma optical

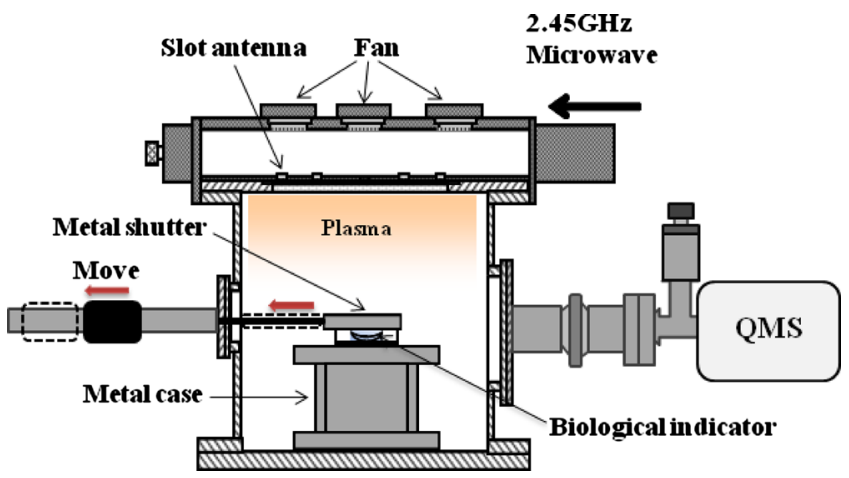

FIG. 1. (Color online) Schematic drawing of experimental setup. 


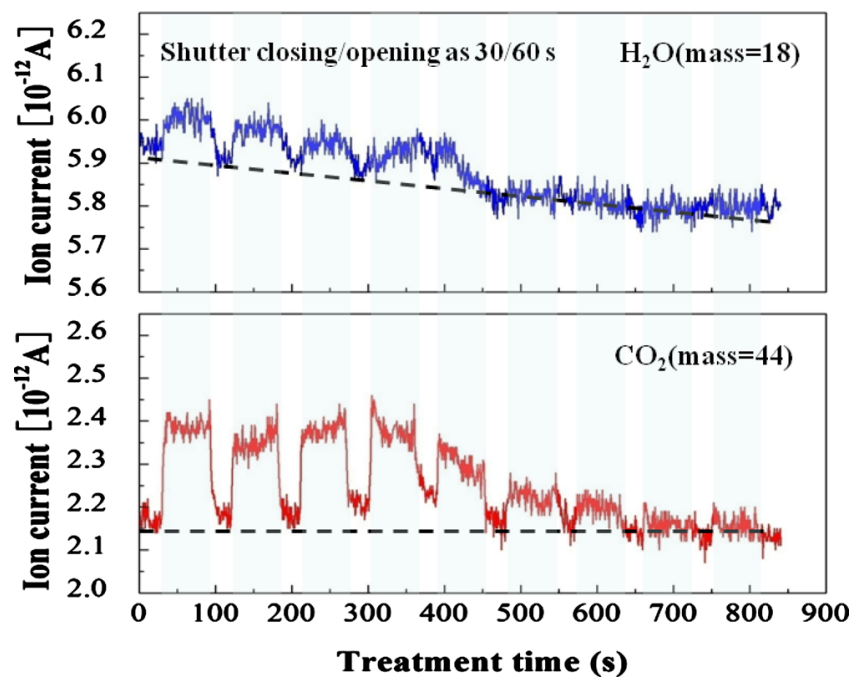

FIG. 2. (Color online) Time evolution of $\mathrm{H}_{2} \mathrm{O}$ and $\mathrm{CO}_{2}$ components during Geobacillus stearothermophilus samples were irradiated by $\mathrm{O}_{2}$ plasma.

emission. The shutter was controlled with closing/opening time as $30 \mathrm{~s} / 60 \mathrm{~s}$ and the shutter was closed at the beginning of experiment. The volatile compounds of microorganisms during the plasma exposure were measured by QMS (Pfeiffer Vacuum, Prisma ${ }^{\mathrm{TM}}$ QMS 200). In order to investigate the etching efficiency, we varied the net microwave power in $400 \mathrm{~W}, 600 \mathrm{~W}$, and $800 \mathrm{~W}$, respectively. In each condition, some of the B.I. samples were treated under a LiF filter (having the optical transmission at $\lambda>120 \mathrm{~nm}$ ) to block the plasma particles and some B.I. samples were directly exposed to the plasma without the $\mathrm{LiF}$ filter. During plasma discharges, the stage temperature was monitored with a thermo label attached to the rear surface of the glass Petri dish. After the plasma treatment, the samples were washed with $1.5 \mathrm{ml}$ of Brain-Heart Infusion solution in the test tube for colony count measurement. Morphological changes in spores by plasma treatment were observed by SEM (Hitachi, S-3000N). For the optical emission spectroscopy (OES) measurement, the vacuum ultraviolet (VUV) to IR monochromator systems (Acton Research Corporation, VM-502) were used.

Because the etching by-product was small amounts, we used the multiple ion detection operation mode of QMS, where the temporal changes in the specific mass components were simultaneously monitored. In order to obtain enough signal intensity, twenty B.I. samples were used each time. The evolutions of the appropriate mass numbers of byproducts expected from the components of bacteria were measured during plasma treatment. Figure 2 shows the time evolution of the $\mathrm{H}_{2} \mathrm{O}(\mathrm{m}=18)$ and $\mathrm{CO}_{2}(\mathrm{~m}=44)$ components, during the period B.I. samples were irradiated by $\mathrm{O}_{2}$ plasma at a microwave power of $600 \mathrm{~W}$. As opening the shutter first after getting stable oxygen plasma, it is clearly seen that the ion currents of the $\mathrm{H}_{2} \mathrm{O}$ and $\mathrm{CO}_{2}$ significantly increased from original values to each maximum. Through several rounds with shutter closing/opening times of $30 \mathrm{~s} / 60 \mathrm{~s}$, the changes in $\mathrm{H}_{2} \mathrm{O}$ and $\mathrm{CO}_{2}$ were gradually reduced, and the signals were almost back to the original levels at last. These byproducts were apparently originated from the components of spore coats via the chemical etching process by oxygen radicals. In addition to the mass components of $m=18$ and 44 ,

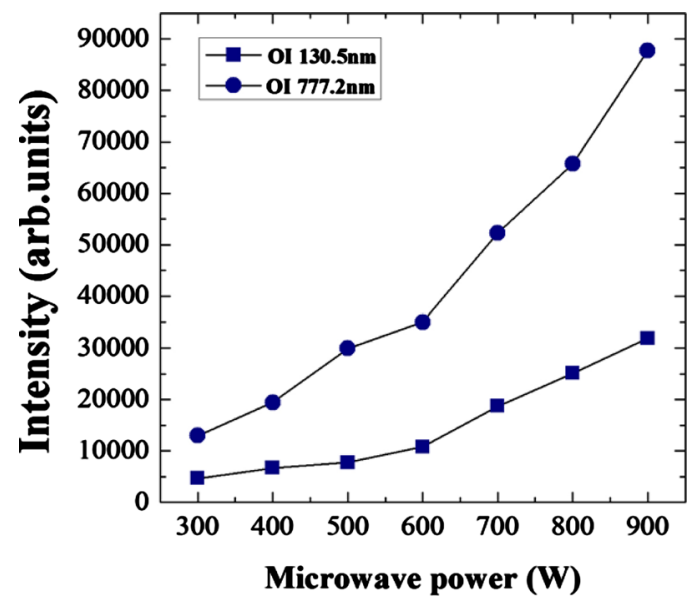

FIG. 3. (Color online) Intensities of $\mathrm{O}$ atoms at 130.5 and $777.2 \mathrm{~nm} \mathrm{ob}-$ served by OES as functions of net input power.

we also observed a component of $\mathrm{m}=28$, which is plausibly considered as CO.

In order to investigate the effect of reactive species on the spore inactivation, the power dependence of oxygen emission lines were studied by the OES. The two main lines of atomic oxygen which correspond to the transition $3 s^{3} \mathrm{~S}$ $\rightarrow 2 p^{43} \mathrm{P}$ at $130.5 \mathrm{~nm}$ (Ref. 10) and the transition $3 s^{5} \mathrm{~S}$ $\rightarrow 3 p^{5} \mathrm{P}$ at $777.2 \mathrm{~nm}$ were used for monitoring the excited oxygen atoms. The net microwave power controlled in operational ranges of 300-900 $\mathrm{W}$ raised the intensity of $\mathrm{O}$ at 130.5 and $777.2 \mathrm{~nm}$, as shown in Fig. 3. With an increase in input microwave power, optical emission intensities were roughly linearly increased. Thereby, it is expected that the production of the reactive oxygen species promotes the process of chemical etching with an increase in net microwave power. $^{11}$

Figure 4 shows the results of colony forming units (CFUs) of the Geobacillus stearothermophilus spores treated by oxygen plasma without and with the LiF filter at $400 \mathrm{~W}$, $600 \mathrm{~W}$, and $800 \mathrm{~W}$, respectively. The treatment temperature in all the cases was maintained below $65^{\circ} \mathrm{C}$ by on/off plasma operation, where plasma on- and off-time were 1 $\mathrm{min} / 2 \mathrm{~min}$, respectively. It is noted here that the survival curves show a multislope, the first segment is related to the

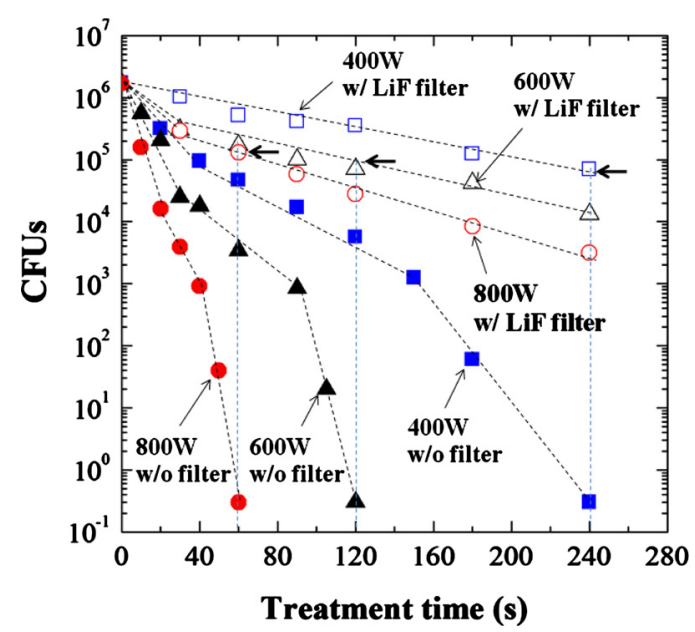

FIG. 4. (Color online) Survival curves of Geobacillus stearothermophilus treated with and without a $\mathrm{LiF}$ filter by $\mathrm{O}_{2}$ plasma at different net input powers of $400 \mathrm{~W}, 600 \mathrm{~W}$, and $800 \mathrm{~W}$, respectively. 

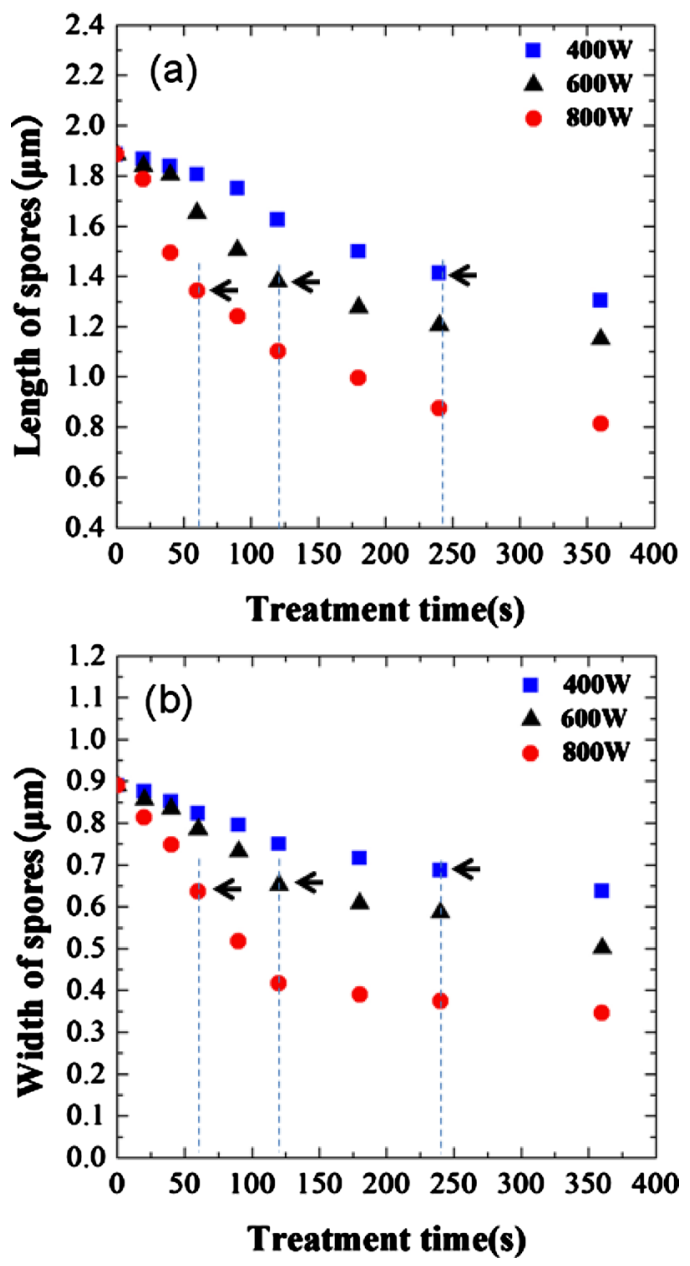

FIG. 5. (Color online) SEM and QMS analyses showing (a) length and (b) width of spore versus $\mathrm{O}_{2}$ plasma treatment time at different net input powers.

inactivation of isolated spores, while the second one may have to do with clamped spores. ${ }^{12,13}$ When the LiF filter was set above the B.I. samples, the CFUs obviously decreased with treatment time. About $90 \%$ spores were killed by only VUV/UV radiation at each six-log reduction time for direct plasma exposure, as shown by arrows in Fig. 4. It means that the VUV emission of atomic oxygen at $130.5 \mathrm{~nm}$ could contribute to the spore mortality, it might be because the VUV/UV high energy photons have enough energies to break $\mathrm{C}-\mathrm{C}(\sim 3.4 \mathrm{eV})$ or $\mathrm{C}-\mathrm{H}(\sim 4.1 \mathrm{eV})$ bonds of DNA strands. ${ }^{14,15}$ Because the typical depth of photochemical reaction is restricted to thin layer, the deactivations by VUV/UV photons are rather restricted in the case of the clamped spores. The oxygen radicals interact with the outermost layer of the spore and the topmost material of spore to reduce any shadowing of the incident UV light.

In order to study the etching effect of the spores subjected to the inactivation process, SEM and QMS analyses were performed. The SEM statistical analysis of the spore length and width was made for 50 spores by measuring the size of spores with micrographs. The results were plotted in Figs. 5(a) and 5(b). It is clearly seen that the length and width of the spores were monotonically decreasing with the treatment times for different microwave powers of 400, 600, and $800 \mathrm{~W}$. The shapes of the initial ellipsoidal structure shrink to slender shapes like jelly beans, and only small fragments left after longer time treatment. Here, it is interesting to note that the six-log reduction of surviving spores was achieved at each plasma treatment time (plotted by dashed lines), when the spore etching was not completed, but still on the way. From Figs. 5(a) and 5(b), it is seen that the shapes of etched spores at the six-reduction times were almost the same for different powers, indicated by arrows, that is, length was $1.35-1.40 \mu \mathrm{m}$ and width was $0.65-0.70 \mu \mathrm{m}$, respectively. After these erosion stages, all the spores did not indicate any germination processes even under the nutrient incubation condition. These results are very important to understand the inactivation mechanism of spore-forming bacteria by the oxygen plasma. It is well known in the biochemical field that the germination of spores occurs when the germinant receptors located in the inner membrane of the spores were triggered by the specific nutrient germinants, such as L-Alanine or a mixture of D-glucose, fructose, L-Asparagine, and $\mathrm{KCl} .{ }^{16}$ The inner membrane inside the spore plays an important role to convert from the dormant spores into metabolically active vegetative cells. In other words, the germination of spores could occur no longer, once the inner membranes were damaged by some reason, even though the DNAs inside the core were not damaged by UV emission or radicals directly. The present results suggest the possibility that the inner membranes were directly damaged by the oxygen erosion process.

This work was partly supported by Grant-in-Aid for Scientific Research (Grant No. 2111010) from Japan Society for the Promotion of Science (JSPS).

${ }^{1}$ R. M. Boucher, U.S. Patent No. 4,207,286 (10 June 1980).

${ }^{2}$ A. A. Bol'shakov, B. A. Cruden, R. Mogul, M. V. V. S. Rao, A. P. Sharma, B. N. Khare, and M. Meyyappan, AIAA J. 42, 823 (2004).

${ }^{3}$ M. Moisan, J. Barbeau, S. Moreau, J. Pelletier, M. Tabrizian, and L'H. Yahia, Int. J. Pharm. 226, 1 (2001).

${ }^{4}$ B. J. Park, D. H. Lee, J. C. Park, I. S. Lee, K. Y. Lee, S. O. Hyun, M. S. Chun, and K. H. Chung, Phys. Plasmas 10, 4539 (2003).

${ }^{5}$ S. Perni, G. Shama, J. L. Hobman, P. A. Lund, C. J. Kershaw, G. A. Hidalgo-Arroyo, C. W. Penn, X. Deng, J. L. Walsh, and M. G. Kong, Appl. Phys. Lett. 90, 073902 (2007).

${ }^{6}$ M. G. Kong, G. Kroesen, G. Morfill, T. Nosenko, T. Shimizu, J. van Dijk, and J. L. Zimmermann, New J. Phys. 11, 115012 (2009).

${ }^{7}$ M. Nagatsu, F. Terashita, H. Nonaka, L. Xu, T. Nagata, and Y. Koide, Appl. Phys. Lett. 86, 211502 (2005).

${ }^{8}$ Y. Zhao, M. K. Singh, A. Ogino, and M. Nagatsu, Thin Solid Films 518, 3590 (2010).

${ }^{9}$ H. Y. Zhou, J. Watanabe, M. Miyake, A. Ogino, M. Nagatsu, and R. J. Zhan, Diamond Relat. Mater. 16, 675 (2007).

${ }^{10}$ L. G. Piper, M. A. A. Clyne, and P. B. Monkhouse, J. Chem. Soc., Faraday Trans. 78, 1373 (1982).

${ }^{11}$ J. R. Chen, Low Temperature Plasma Chemistry and its Application (Science, Beijing, 2001).

${ }^{12}$ X. T. Deng, J. J. Shi, G. Shama, and M. G. Kong, Appl. Phys. Lett. 87, 153901 (2005).

${ }^{13}$ M. K. Singh, A. Ogino, and M. Nagatsu, New J. Phys. 11, 115027 (2009)

${ }^{14}$ N. Munakata, M. Sato, and K. Hieda, Photochem. Photobiol. 54, 761 (1991)

${ }^{15}$ C. Lindberg and G. Horneck, J. Photochem. Photobiol., B 11, 69 (1991).

${ }^{16}$ S. J. Foster and K. Johnstone, in Regulation of Prokaryotic Development, edited by I. Smith, R. A. Slepecky, and P. Setlow (American Society for Microbiology, Washington, 1989), pp. 89-108. 